\title{
Can waist circumference be a predictor of bone mineral density independent of BMI in middle-aged adults?
}

\author{
Ying Hua ${ }^{1}$, Jinqiong Fang ${ }^{1}$, Xiaocong Yao $^{2}$ and Zhongxin Zhu ${ }^{2,3}$ \\ ${ }^{1}$ Department of Administrative Office, The First People's Hospital of Xiaoshan District, Xiaoshan Affiliated Hospital of Wenzhou Medical University, \\ Hangzhou, Zhejiang, China \\ 2Department of Osteoporosis Care and Control, The First People's Hospital of Xiaoshan District, Xiaoshan Affiliated Hospital of Wenzhou Medical \\ University, Hangzhou, Zhejiang, China \\ ${ }^{3}$ Department of Clinical Research Center, The First People's Hospital of Xiaoshan District, Xiaoshan Affiliated Hospital of Wenzhou Medical University, \\ Hangzhou, Zhejiang, China
}

Correspondence should be addressed to Z Zhu: orthozzx@163.com

\begin{abstract}
Background: Obesity and osteoporosis are major public health issues globally. The prevalence of these two diseases prompts the need to better understand the relationship between them. Previous studies, however, have yielded controversial findings on this issue. Therefore, our aim in this study was to evaluate the independent association between waist circumference (WC), as a marker of obesity, and the bone mineral density (BMD) of the lumbar spine among middle-aged adults using data from the National Health and Nutrition Examination Survey (NHANES).

Methods: Our analysis was based on NHANES data from 2011 to 2018, including 5084 adults, 40-59 years of age. A weighted multiple linear regression analysis was used to evaluate the association between WC and lumbar BMD, with smooth curve fitting performed for non-linearities.

Results: After adjusting for BMI and other potential confounders, WC was negatively associated with lumbar BMD in men ( $\beta=-2.8,95 \% \mathrm{Cl}$ : -4.0 to -1.6$)$ and premenopausal women ( $\beta=-2.6,95 \% \mathrm{Cl}:-4.1$ to -1.1 ). On subgroup analysis stratified by $\mathrm{BMI}$, this negative association was more significant in men with a $\mathrm{BMI} \geq 30 \mathrm{~kg} / \mathrm{m}^{2}(\beta=-4.1$, $95 \% \mathrm{Cl}:-6.3$ to -2.0 ) and in pre- and postmenopausal women with a $\mathrm{BMI}<25 \mathrm{~kg} / \mathrm{m}^{2}$ (premenopausal women: $\beta=-5.7,95 \% \mathrm{Cl}$ : -9.4 to -2.0 ; postmenopausal women: $\beta=-5.6$, $95 \% \mathrm{Cl}:-9.7$ to -1.6$)$. We further identified an inverted $\mathrm{U}$-shaped relationship among premenopausal women, with a point of inflection at WC of $80 \mathrm{~cm}$. Conclusions: Our study found an inverse relationship between WC and lumbar BMD in middle-aged men with $\mathrm{BMI} \geq 30 \mathrm{~kg} / \mathrm{m}^{2}$, and women with $\mathrm{BMI}<25 \mathrm{~kg} / \mathrm{m}^{2}$.
\end{abstract}

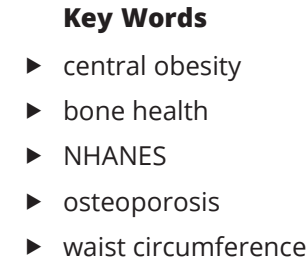

Endocrine Connections (2021) 10, 1307-1314

\section{Introduction}

Osteoporosis, characterized by a reduced bone mass and deterioration in the microarchitecture of bone (1), is a growing concern in aging societies (2). Osteoporosis is diagnosed using bone mineral density (BMD) measurements, most commonly obtained by dualenergy x-ray absorptiometry (DXA) (3). Considering the increasing burden of osteoporosis with aging of the general population, identifying the risk factors for a lower BMD would be important for the prevention of osteoporosis.

Obesity is a major medical problem worldwide (4). Previous research provided evidence of a strong positive correlation between BMD and the BMI (5). Although this 
relationship was first interpreted as a possible protective effect of obesity on bone health, more recent research has revealed a positive association between obesity and bone fractures (6). Waist circumference (WC), which is an easyto-determine clinical parameter, has been proposed to assess central obesity in epidemiological surveys (7), with decrease in WC recommended as a critically important treatment target for reducing adverse health risks (8). However, studies regarding the relationship between WC and BMD are limited, with controversial findings having been reported $(9,10,11,12)$. What is known is that bone mass reaches its peak around the age of 30 years, followed by a slow rate decrease starting around the age of 40 years (13). Therefore, the loss of bone mass during middle-age may play a crucial role in the onset of osteoporosis at an older age. Hence, the objective of our study was to evaluate the independent association between WC and BMD among middle-aged adults using data from the National Health and Nutrition Examination Survey (NHANES).

\section{Methods}

\section{Data sources and study population}

Since 1999, NHANES surveys have been conducted every 2 years to assess the health and nutritional status of the non-institutional population of the United States, using a complex, stratified, and multistage probability sampling design. NHANES survey obtained a nationally representative sample of about 5000 people each year, with data released in 2-year cycles. This survey combines interviews, which consists of demographic, socioeconomic, dietary, and health-related questions, and physical examinations, which included medical, dental, physiological measurements, and laboratory tests. The data give researchers important clues to the causes of the disease and are publicly available on the internet by researchers throughout the world. We combined data from four waves of the NHANES, conducted between 2011 and 2018.

For our study, the population (total participants, $n=39,156)$ was limited to middle-aged adults, $40-59$ years of age $(n=7383)$. Cases with missing WC data $(n=589)$, lumbar BMD data $(n=1115)$, as well as individuals with cancer ( $n=328)$, a WC $\geq 130 \mathrm{~cm}(n=261)$, or a BMI $\geq 50 \mathrm{~kg} /$ $\mathrm{m}^{2}(n=6)$, were excluded. After screening, the data of 5084 individuals were included in the final analysis (Fig. 1). This observational study was approved by the National Center for Health Statistics, and each participant provided the written consent.

\section{Evaluation of exposure and outcome}

Anthropometric data were collected by trained health technicians in the mobile examination center (MEC). Relevant to our study is the measure of WC, using a method previously described (14). WC was measured with individuals in the standing position, arms crossed across their chest (as to place their hands on opposite shoulders). The iliac crests were palpated bilaterally, and a horizontal line was drawn just above the uppermost lateral border of the right ilium. The midaxillary line was then drawn on the right. The measuring tape was positioned in the horizontal plane at the point of intersection between the two lines. WC was then measured (to the nearest $0.1 \mathrm{~cm}$ ) at the endpoint of the individual's normal expiration.

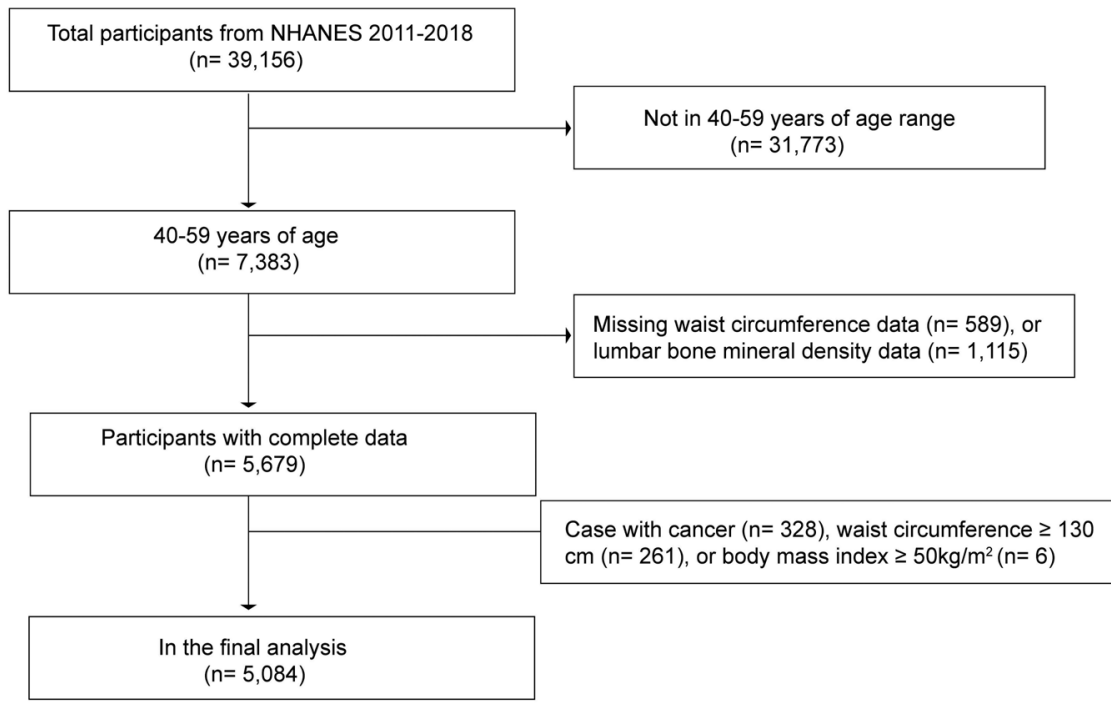

Figure 1

Flowchart of sample selection. https://ec.bioscientifica.com https://doi.org/10.1530/EC-21-0352 (c) 2021 The authors Published by Bioscientifica Ltd

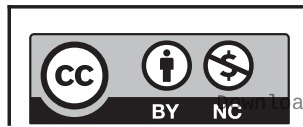

This work is licensed under a Creative Commons Attribution-NonCommercial 4.0 International License. ded from Bioscientifica.com at 04/26/2023 01:15:11PM 
Administered from 2011 to 2018, the whole body DXA measures were obtained using the hologic discovery model A densitometer (Hologic, Inc., Bedford, MA). With standard study-specific protocols and radiologic techniques, the scans were reviewed and analyzed by the shepherd research Lab (15).

\section{Covariates}

The following covariates, part of the NHANES survey, were extracted for inclusion in the analysis: age, ratio of family income to poverty, BMI, diabetes status (defined as following criteria: participant has been told by a doctor to have diabetes or with a $\mathrm{HbA} 1 \mathrm{c} \geq 6.5 \%$ ), total protein, blood urea nitrogen, serum uric acid, serum phosphorus, and serum calcium levels, as continuous variables; and gender, race, educational level, moderate recreational activities, and smoked at least 100 cigarettes in life as categorical variables. Details for obtaining these covariates are available on the NHANES website (https://www.cdc.gov/nchs/nhanes/).

\section{Statistical analysis}

All data analyses were conducted using R version (3.4.3) and EmpowerStats (http://www.empowerstats.com), and with a $P$-value $<0.05$ were considered statistically significant. All estimates were calculated accounting for NHANES sample weights. Continuous variables were expressed as a mean \pm S.D. and categorical variables as percentage. Weighted linear regression models and weighted chi-square tests were used to evaluate between-group differences for continuous variables and categorical variables,

Table 1 The weighted characteristics of middle-aged adults from NHANES 2011 to 2018.

\begin{tabular}{|c|c|c|c|c|c|}
\hline & $\begin{array}{c}\text { Men } \\
(n=2554)\end{array}$ & $\begin{array}{l}\text { Premenopausal } \\
\text { women }(n=1120)\end{array}$ & $\begin{array}{l}\text { Postmenopausal } \\
\text { women }(n=1206)\end{array}$ & $\begin{array}{c}\text { Unrecorded } \\
\text { menstruation }(n=204)\end{array}$ & P value \\
\hline Age (years) & $49.3 \pm 5.8$ & $45.8 \pm 4.0$ & $52.9 \pm 4.8$ & $48.6 \pm 5.6$ & $<0.001$ \\
\hline Race (\%) & & & & & $<0.001$ \\
\hline Non-Hispanic White & 64.1 & 61.1 & 66.1 & 50.7 & \\
\hline Non-Hispanic Black & 10.7 & 12.3 & 13.1 & 13.3 & \\
\hline Mexican American & 9.2 & 10.3 & 6.7 & 8.9 & \\
\hline Other race & 16.0 & 16.3 & 14.0 & 27.1 & \\
\hline Education level (\%) & & & & & $<0.001$ \\
\hline Less than high school & 16.1 & 13.3 & 13.2 & 19.3 & \\
\hline High school & 24.3 & 16.0 & 24.5 & 14.6 & \\
\hline More than high school & 59.6 & 70.6 & 62.3 & 66.1 & \\
\hline Income-poverty ratio & $3.2 \pm 1.6$ & $3.3 \pm 1.6$ & $3.2 \pm 1.6$ & $2.8 \pm 1.7$ & 0.005 \\
\hline $\mathrm{BMI}\left(\mathrm{kg} / \mathrm{m}^{2}\right)$ & $28.6 \pm 4.4$ & $28.6 \pm 6.4$ & $29.0 \pm 5.8$ & $28.1 \pm 6.2$ & 0.072 \\
\hline $\begin{array}{l}\text { Smoked at least } 100 \\
\text { cigarettes in life (\%) }\end{array}$ & & & & & $<0.001$ \\
\hline Yes & 49.6 & 34.6 & 42.3 & 25.8 & \\
\hline No & 50.4 & 65.4 & 57.7 & 74.2 & \\
\hline $\begin{array}{l}\text { Moderate recreational } \\
\text { activities (\%) }\end{array}$ & & & & & 0.094 \\
\hline Yes & 47.5 & 51.2 & 46.5 & 45.1 & \\
\hline No & 52.5 & 48.8 & 53.5 & 54.9 & \\
\hline Diabetes status (\%) & & & & & $<0.001$ \\
\hline Yes & 10.4 & 7.6 & 9.7 & 8.1 & \\
\hline No & 87.4 & 90.4 & 88.0 & 90.4 & \\
\hline Borderline & 2.2 & 2.0 & 2.3 & 1.5 & \\
\hline $\begin{array}{l}\text { Blood urea nitrogen } \\
\text { (mmol/L) }\end{array}$ & $5.1 \pm 1.6$ & $4.1 \pm 1.3$ & $4.8 \pm 1.6$ & $4.5 \pm 1.5$ & $<0.001$ \\
\hline Total protein (g/L) & $71.1 \pm 4.4$ & $70.2 \pm 4.3$ & $70.6 \pm 4.4$ & $70.9 \pm 4.6$ & $<0.001$ \\
\hline Serum uric acid (umol/L) & $354.4 \pm 72.1$ & $265.3 \pm 60.7$ & $285.7 \pm 68.2$ & $263.5 \pm 62.3$ & $<0.001$ \\
\hline $\begin{array}{l}\text { Serum phosphorus } \\
\text { (mmol/L) }\end{array}$ & $1.16 \pm 0.18$ & $1.18 \pm 0.17$ & $1.24 \pm 0.16$ & $1.20 \pm 0.18$ & $<0.001$ \\
\hline Serum calcium (mmol/L) & $2.34 \pm 0.08$ & $2.30 \pm 0.08$ & $2.35 \pm 0.08$ & $2.33 \pm 0.09$ & $<0.001$ \\
\hline Waist circumference (cm) & $101.5 \pm 11.7$ & $94.7 \pm 14.0$ & $97.4 \pm 13.0$ & $93.6 \pm 14.7$ & $<0.001$ \\
\hline $\begin{array}{l}\text { Lumbar bone mineral } \\
\text { density }\left(\mathrm{mg} / \mathrm{cm}^{2}\right)\end{array}$ & $1024.6 \pm 159.3$ & $1070.7 \pm 143.0$ & $987.7 \pm 155.5$ & $1031.6 \pm 132.0$ & $<0.001$ \\
\hline
\end{tabular}

Mean \pm S.D. for continuous variables: $P$ value was calculated by weighted linear regression model. $\%$ for categorical variables: $P$ value was calculated by weighted chi-square test.

https://ec.bioscientifica.com https://doi.org/10.1530/EC-21-0352 (c) 2021 The authors Published by Bioscientifica Ltd

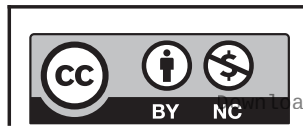

This work is licensed under a Creative Commons Attribution-NonCommercial 4.0 International License. ded from Bioscientifica.com at 04/26/2023 01:15:11PM via free access 
Table 2 Association between waist circumference $(\mathrm{cm})$ and lumbar bone mineral density $\left(\mathrm{mg} / \mathrm{cm}^{2}\right)$ among middle-aged adults from NHANES 2011 to 2018.

\begin{tabular}{l}
\hline \\
\hline Waist circumference \\
Stratified by gender \\
Men $(n=2554)$ \\
Premenopausal women $(n=1120)$ \\
Postmenopausal women $(n=1206)$ \\
Unrecorded menstruation $(n=204)$ \\
Stratified by race \\
Non-Hispanic White $(n=1621)$ \\
Non-Hispanic Black $(n=1183)$ \\
Mexican American $(n=735)$ \\
Other race $(n=1545)$ \\
Diabetes status \\
Yes $(n=655)$ \\
No $(n=4297)$ \\
Borderline $(n=132)$
\end{tabular}

\begin{tabular}{c}
\hline Model 1 \\
\hline$-0.3(-0.6,0.1)$ \\
$-0.6(-1.1,-0.1)^{\star}$ \\
$-0.1(-0.7,0.5)$ \\
$0.8(0.1,1.5)^{\star}$ \\
$-0.4(-1.7,0.8)$ \\
$-0.6(-1.1,0.0)$ \\
$-0.3(-1.0,0.5)$ \\
$-0.3(-1.2,0.5)$ \\
$0.5(-0.1,1.1)$ \\
$0.8(-0.2,1.7)$ \\
$-0.6(-0.9,-0.2)^{* *}$ \\
$1.4(-0.8,3.5)$
\end{tabular}

\begin{tabular}{c}
\hline Model 2 \\
\hline$-0.2(-0.5,0.1)$ \\
$-0.4(-1.0,0.1)$ \\
$-0.3(-0.9,0.3)$ \\
$0.7(-0.0,1.3)$ \\
$-0.6(-1.9,0.6)$ \\
$-0.3(-0.9,0.2)$ \\
$0.0(-0.7,0.7)$ \\
$-0.1(-0.9,0.7)$ \\
$0.7(0.0,1.3)^{*}$ \\
$0.1(-0.9,1.0)$ \\
$-0.4(-0.8,-0.0)^{*}$ \\
$0.7(-1.6,2.9)$
\end{tabular}

\begin{tabular}{l}
$\frac{\text { Model 3 }}{}$ \\
\hline$-2.2(-3.0,-1.4)^{\star \star \star}$ \\
$-3.0(-4.2,-1.8)^{\star \star \star}$ \\
$-2.7(-4.2,-1.3)^{\star \star}$ \\
$-0.7(-2.2,0.8)$ \\
$-0.7(-3.8,2.5)$ \\
$-2.5(-3.8,-1.1)^{\star \star \star}$ \\
$-3.2(-4.9,-1.5)^{\star \star \star}$ \\
$-1.1(-3.0,0.8)$ \\
$0.4(-1.1,2.0)$ \\
$-1.5(-3.6,0.5)$ \\
$-2.6(-3.4,-1.7)^{\star \star *}$ \\
$-1.7(-6.1,2.7)$
\end{tabular}

\begin{tabular}{l}
\hline \multicolumn{1}{c}{ Model 4} \\
\hline$-2.2(-3.0,-1.4)^{\star \star *}$ \\
$-2.8(-4.0,-1.6)^{\star \star *}$ \\
$-2.6(-4.1,-1.1)^{\star \star *}$ \\
$-0.7(-2.2,0.8)$ \\
$0.2(-3.0,3.4)$ \\
$-2.4(-3.8,-1.1)^{\star \star *}$ \\
$-3.7(-5.4,-2.0)^{\star \star *}$ \\
$-1.7(-3.5,0.2)$ \\
$0.4(-1.2,1.9)$ \\
$-1.2(-3.2,0.8)$ \\
$-2.4(-3.2,-1.5)^{\star \star *}$ \\
$-1.1(-5.9,3.7)$
\end{tabular}

Model 1: no covariates were adjusted. Model 2: age, gender, and race were adjusted. Model 3: model 2 plus BMI were adjusted. Model 4: model 3 plus education level, income-poverty ratio, moderate recreational activities, smoked at least 100 cigarettes in life, diabetes status, blood urea nitrogen, total protein, serum uric acid, serum phosphorus, and serum calcium were adjusted. In the subgroup analysis stratified by gender, race or diabetes status, the model is not adjusted for the stratification variable itself.

$\star P<0.05, * \star P<0.01, * \star * P<0.001$

respectively. A weighted multiple linear regression analysis was performed to evaluate the independent association between WC and lumbar BMD. Four models were built to provide statistical inference: model 1, no adjustment for covariates; model 2, adjusted for age, gender, and race; model 3, adjusted for covariates in model 2 plus BMI; and model 4 , adjustment for all covariates. Smooth curve fitting was used to address local non-linearities in the models. If the relationship between WC and BMD was non-linear, a two-piecewise regression was performed to determine the threshold effect of WC on lumbar BMD.

\section{Results}

\section{Characteristics of the study population}

The weighted characteristics of the study sample are presented in Table 1. The study sample of 5084 individuals included 2554 men (mean age, 49.3 years), 1120 premenopausal women (mean age, 45.8 years), 1206 postmenopausal women (mean age, 52.9 years), and 204 women with unrecorded menstrual status. Compared to premenopausal women, men and postmenopausal women had higher levels of total protein, blood urea

Table 3 Association between waist circumference $(\mathrm{cm})$ and lumbar bone mineral density $\left(\mathrm{mg} / \mathrm{cm}^{2}\right)$ among middle-aged adults from NHANES 2011 to 2018, stratified by BMI.

\begin{tabular}{|c|c|c|c|c|}
\hline & Model 1 & Model 2 & Model 3 & Model 4 \\
\hline \multicolumn{5}{|l|}{ Men } \\
\hline $\mathrm{BMI}\left(<25 \mathrm{~kg} / \mathrm{m}^{2}\right)(n=608)$ & $-2.7(-4.3,-1.0)^{\star *}$ & $-1.3(-3.1,0.4)$ & $-1.6(-4.1,0.9)$ & $-2.0(-4.5,0.6)$ \\
\hline BMI $\left(25-29.9 \mathrm{~kg} / \mathrm{m}^{2}\right)(n=1,091)$ & $-1.3(-2.8,0.2)$ & $-1.6(-3.1,-0.1)^{*}$ & $-2.5(-4.5,-0.5)^{*}$ & $-1.8(-3.8,0.2)$ \\
\hline BMI $\left(\geq 30 \mathrm{~kg} / \mathrm{m}^{2}\right)(n=855)$ & $-1.3(-2.8,0.1)$ & $-1.5(-2.9,-0.1)^{*}$ & $-4.5(-6.5,-2.4)^{\star * *}$ & $-4.1(-6.3,-2.0)^{* * *}$ \\
\hline \multicolumn{5}{|l|}{ Premenopausal women } \\
\hline $\mathrm{BMI}\left(<25 \mathrm{~kg} / \mathrm{m}^{2}\right)(n=359)$ & $-1.2(-3.9,1.5)$ & $-0.9(-3.7,1.8)$ & $-6.2(-9.7,-2.7)^{\star \star \star}$ & $-5.7(-9.4,-2.0)^{\star \star}$ \\
\hline BMI $\left(25-29.9 \mathrm{~kg} / \mathrm{m}^{2}\right)(n=317)$ & $-0.8(-3.3,1.7)$ & $-0.6(-3.1,1.8)$ & $-1.5(-4.3,1.3)$ & $-0.9(-3.8,2.0)$ \\
\hline $\mathrm{BMI}\left(\geq 30 \mathrm{~kg} / \mathrm{m}^{2}\right)(n=444)$ & $-0.0(-1.4,1.3)$ & $-0.6(-2.0,0.7)$ & $-2.1(-4.1,-0.2)^{*}$ & $-2.1(-4.2,0.0)$ \\
\hline \multicolumn{5}{|l|}{ Postmenopausal women } \\
\hline BMI $\left(<25 \mathrm{~kg} / \mathrm{m}^{2}\right)(n=299)$ & $1.2(-1.7,4.1)$ & $0.8(-2.0,3.5)$ & $-5.9(-9.7,-2.1)^{\star *}$ & $-5.6(-9.7,-1.6)^{\star *}$ \\
\hline BMI $\left(25-29.9 \mathrm{~kg} / \mathrm{m}^{2}\right)(n=370)$ & $0.2(-2.1,2.5)$ & $0.6(-1.7,2.9)$ & $-0.3(-3.3,2.6)$ & $-1.4(-4.4,1.7)$ \\
\hline $\mathrm{BMI}\left(\geq 30 \mathrm{~kg} / \mathrm{m}^{2}\right)(n=537)$ & $0.2(-1.3,1.6)$ & $-0.0(-1.5,1.5)$ & $0.2(-1.8,2.1)$ & $0.5(-1.5,2.5)$ \\
\hline
\end{tabular}

Model 1: no covariates were adjusted. Model 2: age and race were adjusted. Model 3: model 2 plus BMI were adjusted. Model 4: model 3 plus education level, income-poverty ratio, moderate recreational activities, smoked at least 100 cigarettes in life, diabetes status, blood urea nitrogen, total protein, serum uric acid, serum phosphorus, and serum calcium were adjusted.

$\star P<0.05, * * P<0.01, * * * P<0.001$.

https://ec.bioscientifica.com

https://doi.org/10.1530/EC-21-0352 (c) 2021 The authors Published by Bioscientifica Ltd

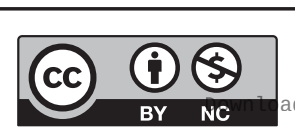

This work is licensed under a Creative Commons Attribution-NonCommercial 4.0 International License. ded from Bioscientifica.com at 04/26/2023 01:15:11PM via free access 

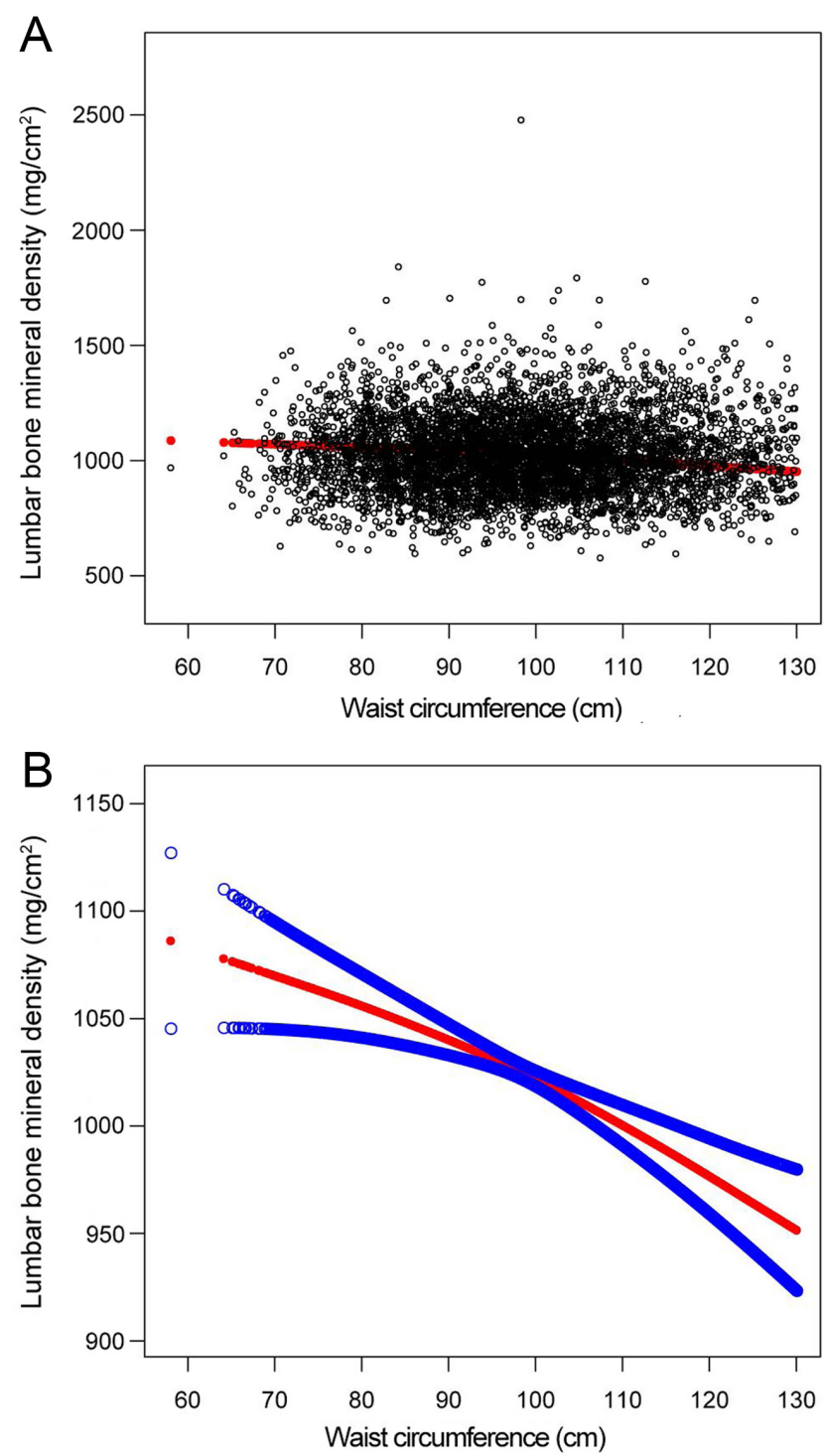

Figure 2

Association between waist circumference and lumbar bone mineral density. (A) Each black point represents a sample. (B) Solid rad line represents the smooth curve fit between variables. Blue bands represent the $95 \% \mathrm{Cl}$ from the fit. Age, gender, race, BMI, education level, incomepoverty ratio, moderate recreational activities, smoked at least 100 cigarettes in life, diabetes status, blood urea nitrogen, total protein, serum uric acid, serum phosphorus, and serum calcium were adjusted.

nitrogen, serum uric acid, serum calcium, a greater WC, and lower lumbar BMD.

\section{Association between WC and lumbar BMD}

Table 2 represents the association between WC and lumbar BMD for the four linear regression models. In models 1 and 2, there was no significant association between WC and lumbar BMD. However, this association became negative after adjusting for BMI and all other covariates (model 3: $\beta=-2.2,95 \%$ CI: -3.0 to -1.4 ; model $4: \beta=-2.2,95 \% \mathrm{CI}$ : --3.0 to -1.4$)$.

On a subgroup analysis stratified by gender, WC was negatively associated with lumbar BMD in men $(\beta=-2.8$, 95\% CI: -4.0 to -1.6$)$ and premenopausal women ( $\beta=-2.6,95 \% \mathrm{CI}:-4.1$ to -1.1 ) in the fully adjusted model. On subgroup analysis stratified by race, the negative association between WC and lumbar BMD was retained in Non-Hispanic Whites $(\beta=-2.4,95 \% \mathrm{CI}:-3.8$ to -1.1 ) and Non-Hispanic Blacks ( $\beta=-3.7,95 \% \mathrm{CI}:-5.4$ to -2.0 ). In the subgroup analysis stratified by diabetes status, this negative association remained significant in non-diabetic participants ( $\beta=-2.4,95 \% \mathrm{CI}:-3.2$ to -1.5 ).

As the BMI was a strong confounding factor, we performed a subgroup analysis stratified by BMI (Table 3). In this subanalysis, the negative association between WC and lumbar BMD was more significant in men with a $\mathrm{BMI} \geq 30 \mathrm{~kg} / \mathrm{m}^{2}(\beta=-4.1,95 \% \mathrm{CI}$ : -6.3 to -2.0$)$ and in pre- and postmenopausal women with a BMI $<25 \mathrm{~kg} / \mathrm{m}^{2}$ (premenopausal women: $\beta=-5.7,95 \% \mathrm{CI}$ : -9.4 to -2.0 ; postmenopausal women: $\beta=-5.6,95 \% \mathrm{CI}:-9.7$ to -1.6$)$.

As BMI and WC are collinear in nature, we further evaluated the association between BMI and WC and lumbar BMD, respectively (Supplementary Figs 1 and 2).

\section{Non-linearity in the association between WC and lumbar BMD}

Smooth curve fittings were performed to characterize the non-linear relationship between WC and lumbar BMD (Figs 2 and 3). Among premenopausal women, the association between WC and lumbar BMD was an inverted U-shaped curve. The point of inflection was identified at 80 cm using a two-piecewise linear regression model (Table 4).

\section{Discussion}

Our data revealed an inverse relationship between WC and lumbar BMD among middle-aged men and premenopausal women, and with an inverted U-shaped relationship among premenopausal women, with a point of inflection at a WC of $80 \mathrm{~cm}$.

Obesity and osteoporosis have become major health issues globally. The prevalence of these two diseases prompts theneed tobetter understand the relationshipbetween them. To date, evidence on the relationship between WC and BMD has remained controversial. In a recent cross-sectional study of 4663 Chinese males, Chen et al. (9) identified WC to be a 


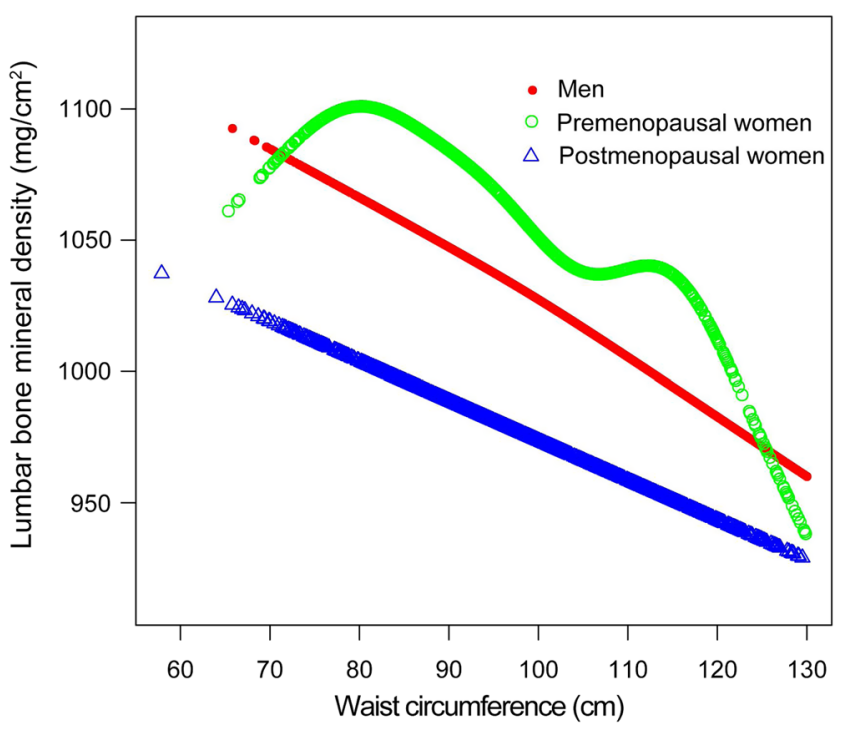

Figure 3

Association between waist circumference and lumbar bone mineral density, stratified by gender. Age, race, BMI, education level, incomepoverty ratio, moderate recreational activities, smoked at least 100 cigarettes in life, diabetes status, blood urea nitrogen, total protein, serum uric acid, serum phosphorus, and serum calcium were adjusted.

negative predictor of calcaneal BMD among males $\geq 40$ years of age, with a normal weight to minimize the influence of BMI on the measured relationship between WC and BMD. In a Korean community-based, cross-sectional study including 3042 adults $>40$ years of age, Kim et al. (10) identified a negative association between WC and BMD after adjusting for age and weight. This negative association between WC and BMD was confirmed in another community-based study in Korea, including individuals aged $\geq 50$ years (16). By comparison, a cross-sectional study conducted in Turkey reported a significant positive association between WC and total hip BMD, but a negative association with non-weight-bearing sites (11). A community-based study

Table 4 Threshold effect analysis of waist circumference $(\mathrm{cm})$ on lumbar bone mineral density $\left(\mathrm{mg} / \mathrm{cm}^{2}\right)$ in premenopausal women using two-piecewise linear regression model.

\begin{tabular}{l}
\hline Lumbar bone mineral density \\
\hline Premenopausal women \\
Fitting by standard linear model \\
Fitting by two-piecewise linear model \\
Inflection point \\
Waist circumference $<80(\mathrm{~cm})$ \\
waist circumference $>80(\mathrm{~cm})$ \\
Log likelihood ratio
\end{tabular}

Adjusted $\boldsymbol{\beta}(95 \% \mathrm{Cl})$

$-2.6(-4.1,-1.1)$

80

$2.4(-2.7,7.4)$

$-3.1(4.7,-1.5)$ 0.041

Age, race, BMI, education level, income-poverty ratio, moderate recreational activities, smoked at least 100 cigarettes in life, diabetes status, blood urea nitrogen, total protein, serum uric acid, serum phosphorus, and serum calcium were adjusted. conducted in rural regions of Taiwan reported a positive association between WC and lumbar, hip and femoral neck BMD among elderly women (12). Noted differences reflect differences in study design, study population, method for BMD quantification and site of measurement, and control of confounding variables.

WC has been used as a measure of abdominal obesity, with the BMI providing a measure of general obesity. It is widely accepted that abdominal obesity is a better predictor for several adverse health outcomes (17). This might explain differences in findings between our study and those from a recent meta-analysis that showed that a higher BMD, both at the lumbar spine and the femoral neck, among adults with obesity (defined by the BMI) compared to those with a healthy weight (18). BMI and WC are collinear in nature, however, individual with a normal BMI but a large waist is at a higher risk of metabolic disorders (19). Our findings indicate that the inverse association between WC and BMD was independent of BMI. Moreover, this association tends to be different among men and women according to BMI. It may be related to the inherent differences between men and women in fat mass and distribution. Further prospective intervention trials are warranted to confirm this association.

The exact mechanisms of the deleterious effects of obesity on bone are unclear. Replacement of osteoblasts by adipocytes in bone marrow is a possible explanation. Osteoblasts and adipocytes are both derived from bone marrow mesenchymal stem cells, and, thus, increasing adipogenic differentiation decreases osteogenic differentiation (20). Another possible explanation is that obesity-induced hypermetabolism caused by enhanced insulin signaling leads to accelerated metabolic senescence of bone marrow stromal stem cells (21). Despite these possibilities, further studies are needed to explore the molecular mechanism towards the association of WC with BMD. Moreover, our results revealed that men and postmenopausal women had higher levels of serum calcium and lower lumbar BMD than premenopausal women. In another NHANES study for the elderly adults, a similar negative relationship between serum calcium level and BMD has also been reported (22).

The results of our study have a high degree of generalizability as the NHANES survey provides data from a nationally representative sample. Furthermore, the large sample size of our study allowed us to perform subgroup analyses. The limitations of our study also need to be acknowledged. First, the main study limitation is its cross-sectional design. We were unable to assess the causal association between WC and lumbar BMD. Large sample prospective studies are warranted to address causality.

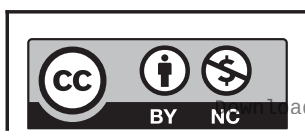

This work is licensed under a Creative Commons Attribution-NonCommercial 4.0 International License. ded from Bioscientifica.com at 04/26/2023 01:15:11PM 
Second, the NHANES database does not include the prevalence of osteoporosis and there were many missing data on hip BMD in the NHANES database from 2011 to 2018. Therefore, we could only use lumbar BMD and not hip BMD or prevalence of osteoporosis. Third, direct measurements of visceral adiposity were not available in this study, which is an inherent limitation. Fourth, we excluded participants with cancer or with a $W C \geq 130 \mathrm{~cm}$ or a $\mathrm{BMI} \geq 50 \mathrm{~kg} / \mathrm{m}^{2}$; therefore, the findings of our study cannot be generalized to these specific populations.

In conclusion, our study found an inverse relationship between WC and lumbar BMD in middle-aged men with $\mathrm{BMI} \geq 30 \mathrm{~kg} / \mathrm{m}^{2}$, in pre- and postmenopausal women with BMI $<25 \mathrm{~kg} / \mathrm{m}^{2}$.

\section{Supplementary materials}

This is linked to the online version of the paper at https://doi.org/10.1530/ EC-21-0352.

\section{Declaration of interest}

The authors declare that there is no conflict of interest that could be perceived as prejudicing the impartiality of the research reported.

\section{Funding}

This work did not receive any specific grant from any funding agency in the public, commercial, or not-for-profit sector.

\section{Ethical statement}

The ethics review board of the National Center for Health Statistics approved all NHANES protocols and written informed consents were obtained from all participants.

\section{Author contribution statement}

All authors made a significant contribution to the work reported, and agreed to be accountable for all aspects of the work.

\section{Acknowledgements}

The authors thank the staff and the participants of the NHANES study for their valuable contributions.

\section{References}

1 Consensus development conference: diagnosis, prophylaxis, and treatment of osteoporosis. American Journal of Medicine 199394 646-650. (https://doi.org/10.1016/0002-9343(93)90218-e)

2 Wang P, Abdin E, Shafie S, Chong SA, Vaingankar JA \& Subramaniam M. Estimation of prevalence of osteoporosis using OSTA and its correlation with sociodemographic factors, disability and comorbidities. International Journal of Environmental Research and Public Health 201916 2338. (https://doi.org/10.3390/ijerph16132338)

3 US Preventive Services Task Force, Curry SJ, Krist AH, Owens DK, Barry MJ, Caughey AB, Davidson KW, Doubeni CA, Epling JW, Kemper AR, et al. Screening for osteoporosis to prevent fractures: US
Preventive Services Task Force recommendation statement. JAMA 2018 319 2521-2531. (https://doi.org/10.1001/jama.2018.7498)

4 GBD 2015 Obesity Collaborators, Afshin A, Forouzanfar MH, Reitsma MB, Sur P, Estep K, Lee A, Marczak L, Mokdad AH, MoradiLakeh M, et al. Health effects of overweight and obesity in 195 countries over 25 years. New England Journal of Medicine 2017377 13-27. (https://doi.org/10.1056/NEJMoa1614362)

5 Gkastaris K, Goulis DG, Potoupnis M, Anastasilakis AD \& Kapetanos G. Obesity, osteoporosis and bone metabolism. Journal of Musculoskeletal and Neuronal Interactions $202020372-381$.

6 Court-Brown CM, Duckworth AD, Ralston S \& McQueen MM. The relationship between obesity and fractures. Injury 201950 1423-1428. (https://doi.org/10.1016/j.injury.2019.06.016)

7 Turcato E, Bosello O, Di Francesco V, Harris TB, Zoico E, Bissoli L, Fracassi E \& Zamboni M. Waist circumference and abdominal sagittal diameter as surrogates of body fat distribution in the elderly: their relation with cardiovascular risk factors. International Journal of Obesity and Related Metabolic Disorders 200024 1005-1010. (https://doi. org/10.1038/sj.ijo.0801352)

8 Ross R, Neeland IJ, Yamashita S, Shai I, Seidell J, Magni P, Santos RD, Arsenault B, Cuevas A, Hu FB, et al. Waist circumference as a vital sign in clinical practice: a consensus statement from the IAS and ICCR Working Group on Visceral Obesity. Nature Reviews: Endocrinology 202016 177-189. (https://doi.org/10.1038/s41574019-0310-7)

9 Chen L, Liang J, Wen J, Huang H, Li L, Lin W, Zong L, Wang N, Cai L, Tang $\mathrm{K}$, et al. Is waist circumference a negative predictor of calcaneal bone mineral density in adult Chinese men with normal weight? Annals of Translational Medicine 20197 201. (https://doi.org/10.21037/ atm.2019.04.71)

$10 \mathrm{Kim}$ JH, Choi HJ, Kim MJ, Shin CS \& Cho NH. Fat mass is negatively associated with bone mineral content in Koreans. Osteoporosis International 201223 2009-2016. (https://doi.org/10.1007/s00198-0111808-6)

11 Ağbaht K, Gürlek A, Karakaya J \& Bayraktar M. Circulating adiponectin represents a biomarker of the association between adiposity and bone mineral density. Endocrine 200935 371-379. (https://doi.org/10.1007/s12020-009-9158-2)

12 Chang CS, Chang YF, Wang MW, Chen CY, Chao YJ, Chang HJ, Kuo PH, Yang YC \& Wu CH. Inverse relationship between central obesity and osteoporosis in osteoporotic drug naive elderly females: the Tianliao Old People (TOP) Study. Journal of Clinical Densitometry 201316 204-211. (https://doi.org/10.1016/j.jocd.2012.03.008)

13 Farrah Z \& Jawad AS. Optimising the management of osteoporosis. Clinical Medicine 202020 e196-e201. (https://doi.org/10.7861/ clinmed.2020-0131)

14 National Health and Nutrition Examination Survey, anthropometry procedures manual. (available at: https://wwwn.cdc.gov/nchs/data/ nhanes/2017-2018/manuals/2017_Anthropometry_Procedures Manual.pdf)

15 Centers for Disease Control and Prevention. National Health and Nutrition Examination Survey, 2018. (available at: https://www.cdc. gov/nchs/nhanes/index.htm)

16 Cui LH, Shin MH, Kweon SS, Choi JS, Rhee JA, Lee YH, Nam HS, Jeong SK, Park KS, Ryu SY, et al. Sex-related differences in the association between waist circumference and bone mineral density in a Korean population. BMC Musculoskeletal Disorders 201415326. (https://doi.org/10.1186/1471-2474-15-326)

17 Traissac P \& El Ati J. Trends in obesity, NHANES 2003-2004 to 20132014: is waist circumference increasing independently of BMI? Obesity 201927 1043. (https://doi.org/10.1002/oby.22492)

18 Qiao D, Li Y, Liu X, Zhang X, Qian X, Zhang H, Zhang G \& Wang C. Association of obesity with bone mineral density and osteoporosis in adults: a systematic review and meta-analysis. Public Health 2020180 22-28. (https://doi.org/10.1016/j.puhe.2019.11.001)

19 Khanna D \& Rehman A. Pathophysiology of obesity. In StatPearls. Treasure Island (FL): StatPearls Publishing LLC, 2021. 
20 Khan AU, Qu R, Fan T, Ouyang J \& Dai J. A glance on the role of actin in osteogenic and adipogenic differentiation of mesenchymal stem cells. Stem Cell Research and Therapy 202011 283. (https://doi. org/10.1186/s13287-020-01789-2)

21 Tencerova M, Frost M, Figeac F, Nielsen TK, Ali D, Lauterlein JL, Andersen TL, Haakonsson AK, Rauch A, Madsen JS, et al. Obesityassociated hypermetabolism and accelerated senescence of bone marrow stromal stem cells suggest a potential mechanism for bone fragility. Cell Reports 201927 2050.e6-2062.e6. (https://doi. org/10.1016/j.celrep.2019.04.066)

22 Liu M, Yao X \& Zhu Z. Associations between serum calcium, 25(OH)D level and bone mineral density in older adults. Journal of Orthopaedic Surgery and Research 201914 458. (https://doi. org/10.1186/s13018-019-1517-y)

Received in final form 24 August 2021

Accepted 15 September 2021

Accepted Manuscript published online 15 September 2021
This work is licensed under a Creative Commons Attribution-NonCommercial 4.0 International License. 